\title{
Cues, strategies, and outcomes: how migrating vertebrates track environmental change
}

\author{
David W Winkler ${ }^{1,2 *}$, Christian Jørgensen ${ }^{3}$, Christiaan Both ${ }^{4}$, Alasdair I Houston ${ }^{5}$, John M McNamara ${ }^{6}$, Douglas J Levey ${ }^{7}$, \\ Jesko Partecke ${ }^{8,9}$, Adam Fudickar ${ }^{8,10}$, Alex Kacelnik ${ }^{11}$, David Roshier ${ }^{12}$ and Theunis Piersma ${ }^{4,13}$
}

\section{Introduction}

Migratory vertebrates adjust their movements in response to environmental change. Throughout their migrations, they gather information, integrate environmental and internal state data, and make decisions about the timing and orientation of migratory movements. Understanding this class of animal decision-making has both basic and applied interest because migratory animals face unique challenges adjusting to anthropogenic environmental changes worldwide. Evolved changes in decision mechanisms necessarily lag behind environmental changes because their evolution is driven by the consequences of resulting actions, and this raises the possibility of major mismatches between behaviour and environmental circumstances when the latter change faster than the pace of natural selection. Yet, migration-decision systems have the capacity for considerable flexibility at the phenotypic level. Distinguishing the evolution of fixed genetic changes from changes that can occur in individual phenotypes requires a better understanding of the mechanisms underlying organismal response. We reflect on such issues, hoping to engender new thinking about the special difficulties that seasonally migrating animals face in times of rapid environmental change. We focus on three key aspects: (1) We distinguish between variations in migratory timing forced upon migrants by overwhelming environmental changes and those that arise from individual "strategic" variation in decision-making. (2) We examine how the availability and reliability of information about environmental quality determine optimal cue choice and cue-response. (3) We highlight how adjustments of individual migration strategies can be made by changes in the decision-making machinery during development,

\footnotetext{
* Correspondence: dww4@cornell.edu

'Department of Ecology and Evolutionary Biology, Corson Hall, Cornell University, Ithaca, NY 14853, USA

${ }^{2}$ Cornell Museum of Vertebrates \& Laboratory of Ornithology, 159 Sapsucker Woods Road, Ithaca, NY 14850, USA

Full list of author information is available at the end of the article
}

dramatically increasing the rate at which migratory strategies can adjust to environmental change.

Global change includes rapid alterations to the distribution and quality of habitats. A major concern about global climate change is that trends in temperature and rainfall will indirectly alter the distribution of resources in time and space and shift the location of sites with specific suites of ecological parameters, potentially over long distances. For organisms with limited opportunities for within-lifespan movements, such as plants, non-flying invertebrates and freshwater organisms, much concern has focused on whether species ranges can keep up with the pace of global change [1-4], and whether pre- and post-shift ranges will be sufficiently connected to allow viable dispersal from the former to the latter [5]. In contrast, animals that regularly traverse large regions with high habitat heterogeneity would presumably be the last ones we should be concerned about with respect to responses to anthropogenic change [6], yet there is evidence that populations of long-distance migrants are under pressure worldwide [7-13]. It appears that adjustments of some migratory species to large-scale environmental changes may not be sufficiently fast to ensure the maintenance of viable populations. Thus, a better understanding of the factors controlling the flexibility of migratory behaviour is important to both basic science and conservation.

Seasonal migration occurs in many animal groups [14-18] but we focus on vertebrates. Comparisons of migratory behaviour across all major vertebrate groups suggest that the considerable navigational and movement capacities on which migration relies are not dedicated adaptations for migration, but appear to be present in closely related groups of species that include both migratory and resident species [19]. A migratory life history can therefore be thought of as a flexible set of strategies, which, in a changing global environment, is exactly what might save populations from extinction. Still, distinguishing between those populations or species that may keep up with global change and those for which we should be concerned, 
requires that we break down a migratory life history into mechanisms, by separating environments, strategies, and the outcomes that arise from their interaction.

In this paper, we first explain our focus on the timing of migratory actions. Then we move on to explore how migratory decisions can be seen as behavioural strategies and grapple with the fact that migratory strategies and their movement outcomes are less directly connected than in other traits. One of the most important causes of this weak connection is that vertebrates must base their movement decisions on a set of environmental cues that are removed in space and time from the environments at the end-points of their migratory journeys, and the reliability of these cues can change over time. As an animal approaches the end of one of its journeys, the cues available should generally be giving more accurate indications of the conditions ahead, and the quality of stopover sites or migratory paths may be judged by their information content in addition to their safety, food supply, etc.. We explore some real-world counter-examples, however, where cues in migration appear to be becoming less reliable indicators of conditions at journey's end. We close with observations and hypotheses about the evolution of cue-responses and how a better understanding of the underlying mechanisms can lead to better understanding of vertebrate migration systems, both in the context of global change and phenotypic evolution more generally.

\section{Review and synthesis}

\section{In seasonal environments, timing is key}

The most important consequence of migration is to keep individuals in favourable environments throughout the varying habitats available on Earth. Rather than adapting to life in a single location with seasonal phenotypic changes, many migrants have evolved the means to move, repeatedly, between regions, to complete their life cycles. And, whether one considers a semelparous salmon preparing to leave its ocean home for a lifeending journey to ancestral spawning grounds or a red bat building body stores for its annual migration to the south, one of the most fundamental decisions they must make is when to move. We concentrate here on migratory timing, as it is one of the most critical, and most general, aspects of decision-making shared by all migrating animals.

Contemporary migrants are species that have, in their evolutionary past, found a match between their seasonal movements and environmental conditions, sometimes over vast distances, even during epochs of large-scale climatic changes. These adjustments could have been through genetic changes underlying migration [20-24] and/or phenotypic plasticity [25-30]. While genetic changes have a generational tempo, in phenotypic plasticity, and especially the category of intra-individual changes termed 'phenotypic flexibility' [31], adjustments can occur within the lifespans of individuals. Both types of change can act on single migratory parameters such as migratory direction or period, or may simultaneously adjust many traits, such as diet, social structure and timing of reproduction. Both genetic change and phenotypic plasticity can thus allow populations to survive profound climate change, but predicting whether they can keep pace with rapid environmental change depends on a better understanding of how genetic and phenotypic pathways for migratory flexibility work and interact.

When an animal 'decides' (in a broad sense, including physiological, non-cognitive, processes) when and where to migrate, it uses mechanisms tuned by evolution to be effective with respect to circumstances in distant sites and later times, but the information that acts as input to such mechanisms is local. For this reason, the control of migratory behaviour incorporates sensitivity to local indicators that predict circumstances far away. What makes matters worse for a migrating animal is that, even though the animal may set out on a route that in the past has led its ancestors to an advantageous destination, reaching that destination may be prevented or delayed by changeable environmental conditions en route. This disjunction in space and time serves to highlight (Figure 1) the distinction between a strategy (attempted departure time as a function of environment and state), an action (the phenotypic manifestation of the strategy, i.e. the actual departure time), and an outcome of the action (the actual journey, including delays and arrival (or not) at the endpoint).

Thus, migration strategies can be seen as the mapping of actions (continued feeding, departure or cessation of migration) on cues (e.g., daylength, feeding or wind conditions). How those actions result in a change in the animal's movements depends on the conditions encountered as a result of the action. In the migration context, the outcomes of strategies have different survival and/or reproductive consequences depending on the environments encountered by the migrant during migration and the timing and location of its journey's end. More clearly than in other organisms, the migrant's observable environment (the collection of cues it uses to guide its behavioural decisions) is different than the fitness-decisive environment in which the fitness consequences of those decisions are assessed (Figure 1; for an earlier treatment of this distinction in time, see [30]). This simple fact is the clearest path for dangerous mismatches that can make existing mechanisms obsolete when the world changes.

\section{Strategies and outcomes}

The action of natural selection is expected to produce approximately optimal patterns of migration. A formalization of this view considers a migrant's decisions, such as 


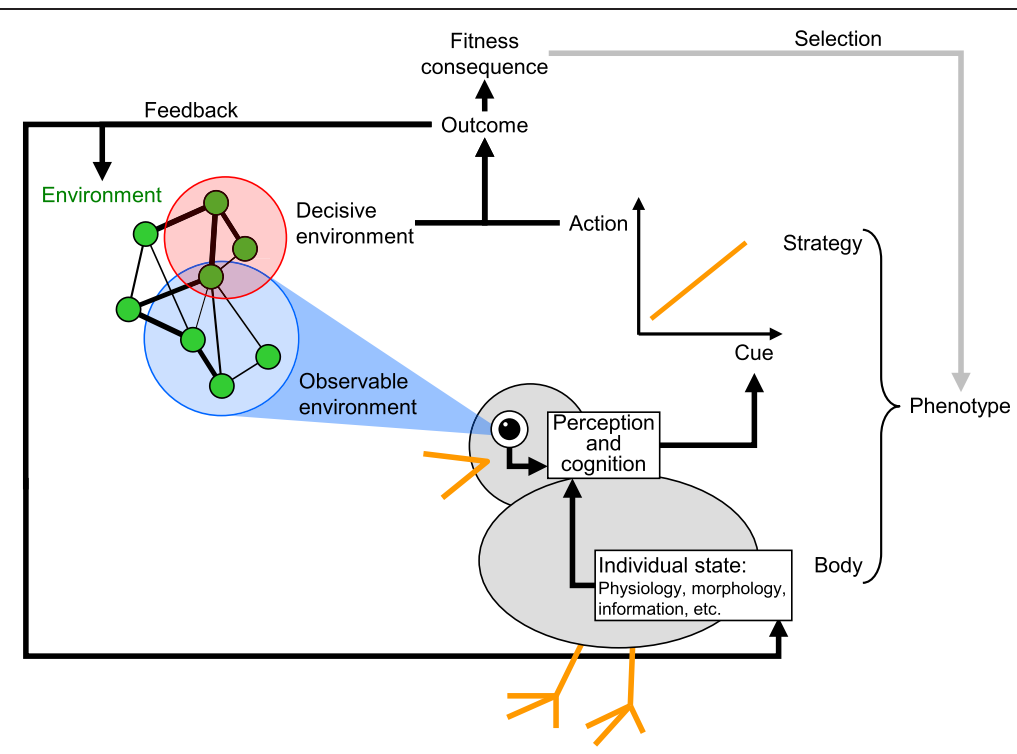

Figure 1 The feedback links between the phenotype (composed of morphology/physiology and the strategy set, see text) and the environment. There is an important distinction between the observable environment, which includes cues for decision-making, and the actual decisive aspects of the environment that determine the outcome, and thus the fitness, associated with the chosen action. Organisms would not have a problem if the observable environment equals the decisive environment, but since these are often distinct in space and time, an organism should respond to cues that are proxies for the decisive environment.

whether to accumulate fat, grow flight muscles or moult, leave a stopover or stay longer to refuel, settle for breeding or keep travelling, and so on [32-37] to be determined by a strategy. A strategy is a rule that specifies the action to be taken in each possible state [38]. A reaction norm specifies how phenotype depends on environmental conditions and hence is a particular sort of strategy [39]. Differences among strategies can be seen as alternatives with different implications for fitness, and the available strategies can be ranked according to these implications. The optimal strategy is the one that maximizes fitness, and several papers have used this state-dependent approach to investigate migration (e.g., [37,40-47]).

The constellation of perceivable stimuli continuously exceeds the set of internal and external cues that are relevant to making a good migration decision, hence the organism must strategically filter and integrate the stimuli it uses to make decisions. This process of sampling sensory input to distill information and generate actions, i.e. the strategy, is fundamental to all sorts of biological problems, but it is often very poorly understood.

Strategies can be difficult to identify in practice. At first sight, one might think that strategies could be measured by observing animals behaving in their environments, but what is most often measured are the outcomes of following a strategy. Even though an optimal strategy is typically a deterministic function of state, the resulting behaviour of a large group of animals that follow the strategy will be highly variable, because outcomes and hence future states have a large stochastic component
[38]. For example, reaching a destination may be prevented or delayed by changeable environmental conditions en route. Furthermore, the same strategy can produce different outcomes in different environments [48], just as the same outcome in different environments might be produced through different [49] or varying strategies (Figure 2), or through a failure to respond to any of the measured environmental variation at all!

Disentangling these possibilities requires experiments and carefully controlled observations. In the case of migration, it becomes important to know whether a migrant that reaches the breeding grounds later than others has done so because it was facing unfavourable winds, or because it followed an alternative strategy selected because of the long-term fitness benefits of such late arrival. Was its distinctive late timing the result of an adaptive strategy, the outcome of environmental noise, or a combination of both? This means that a 'migratory phenotype' is difficult to define. Field workers tend to think of metrics such as an individual's timing of arrival at the breeding or spawning grounds, the locations and durations of stopover sites, movement speed, and migratory route. These aspects of migration can be measured directly, and many biologists would be tempted to think of them as phenotypes connected to genotypes - the variable expression of which across a range of environments can be summarized as a reaction norm [50]. But, more than in most other traits, because of the diverse and variable environments traversed, action and outcome in migration are distinct, and measuring a migratory reaction norm is complicated. 

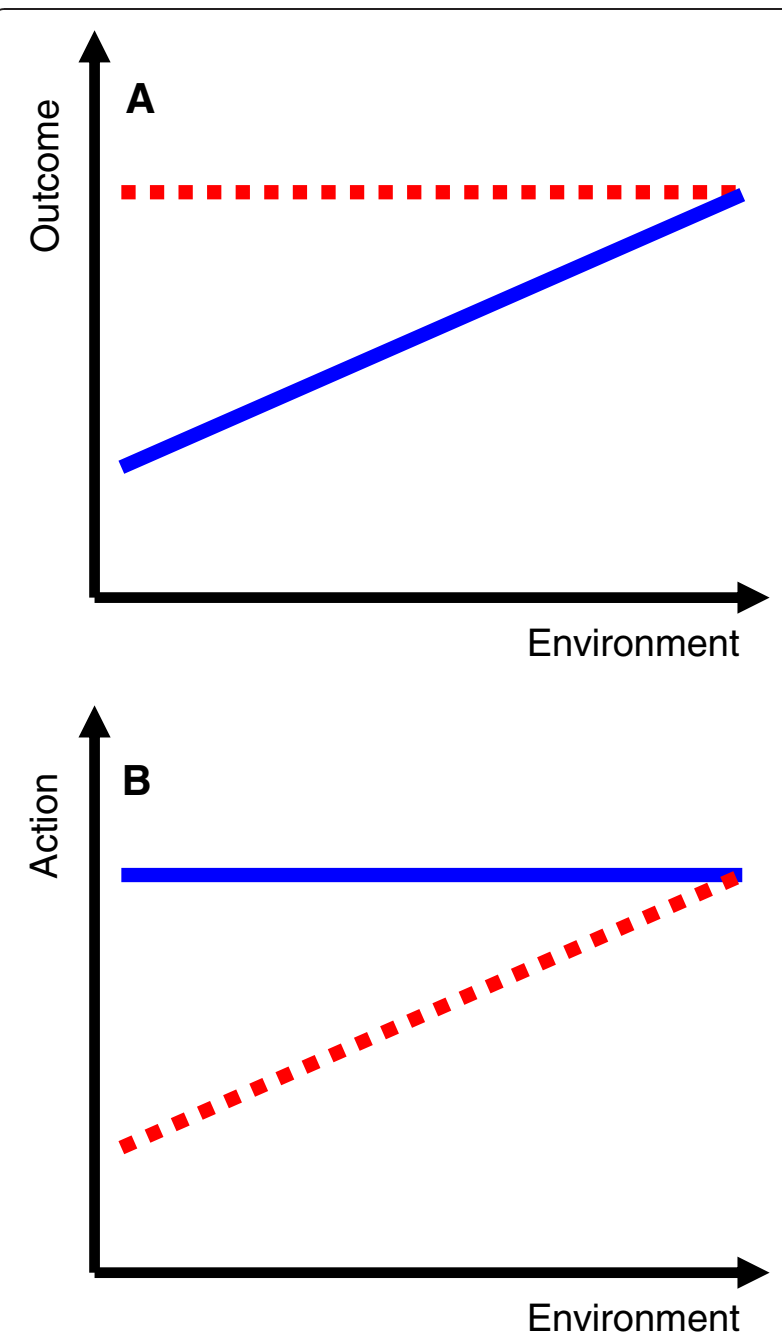

Figure 2 There is not a constant mapping between strategies or actions (B) and outcomes (A). Constant strategies (blue solid lines) can produce variable outcomes across different environments and variable strategies (red dotted lines) may maintain constant outcomes across different environments.

Observations at the end-point of an animal's migration, for instance with the aim of relating outcomes (e.g., arrival times) at the breeding or spawning ground to actions en route, are always complicated by the fact that each of the animals arriving may have arrived there over a different route, and on a different schedule [51,52]. Each migrant's path is the result of a distinctive set of organismal states interacting with a distinctive set of environments, each of which are only points in a multidimensional norm of reaction. Because each animal's path to the migratory endpoint may be unique, it is impossible, even in principle, to place all individuals on a common suite of environments for comparing and summarizing the reaction norm, the set of phenotypes expressed in each. Migratory phenotypes need to be dissected carefully, describing how they relate to variation in cues and internal states. In migratory phenotypes, perhaps more than other phenotypes, actions are conditioned by other aspects of the migrant's state: the timing of departure may depend on a variety of environmental cues (e.g., day length, wind or current conditions, social factors) as well as diverse internal state variables (e.g., locomotory ability, fuel stores, water or osomoregulatory balance, knowledge of the route). To accurately assess the range of actions possible from a given genotype (i.e. strategy), we need to constantly bear in mind these diverse factors affecting a decision or action. Clearly, we can learn a great deal short of this complete dissection, but a robust prediction of the flexibility of migrant response to environmental change will require a much more detailed and nuanced understanding of migratory strategies. A strategy is an abstract statement of how behaviour depends on circumstances, and it is implemented by physiological and psychological mechanisms [53], upon which the behavioral consequences of changes in the migrant's environment depend [42].

Strategies will vary in their degree of plasticity. Strategies can be seen as prescriptions of how to respond to changing circumstances in the world. Often this response will involve learning, and what is learnt will affect the later response to circumstances. Such strategies are likely to be quite plastic in that the outcome of following a strategy will vary a lot, depending on the early environment experienced [54]. This seems to be the case, for example, in the Norwegian spring-spawning herring, Clupea harengus, which has changed feeding migration schedules and overwintering areas repeatedly over the last century [25]. These changes have been most rapid when the population was dominated by young and inexperienced individuals [26]. If the strategy involves imprinting during ontogeny, migration may change from one generation to the next if the imprinting signal changes. Such singlegeneration shifts occur through natal homing in salmonids, where, after the oceanic phase, adults return to the river or stream in which they were born [55].

Conversely, young birds on their first migrations seem often to rely on constant compass headings and photoperiodically dictated schedules, adopting more flexible systems of scheduling and orientation as they gain more experience in subsequent journeys [56-58].

These are only a few examples of the many ways that the connection between strategies and outcomes is conditioned by changes in migrants and in their environments. Each of the intervening links between the observable environment and the cues it provides, through the action, to the fitness-decisive environment in which outcomes are realized (Figure 1); all are in need of further study. But nowhere is the link between environment and organism any stronger than in the world of cues, both internal and external, that the migrant must use to make its movement decisions. 


\section{Cues, their reliability, and the migrant's response}

If migratory strategies are seen as responses to variation in a migrant's state, they place in strong relief the importance of cues as a distilled rendering of the state and situation of the animal. No matter what other aspects of state might be important to strategic modeling, cues are those aspects of state that are sufficiently perceivable and predictive to form the basis for optimal strategic movement decisions. In some cases, predictive cues reflect astronomic regularities unconnected to short-term variability. For instance, photoperiod may be informative because it reflects planetary timing, automatically filtering out noise in local weather or other circumstances that do not correlate with remote circumstances. Thus, photoperiod may have proven informative for centuries to brent geese (Branta bernicla) wintering in Scotland about dates of ice-melting in their Arctic breeding grounds, thousands of kilometers away.

By contrast, ungulates from around the world have very different patterns of annual movements, from residents that stay in a home range of a few kms through nomads that move through an extent of a few hundred kms annually to regular seasonal migrants that cover many hundreds of kms every year (Figure 3) [59,60]. This variation in patterns of movement is strongly correlated with the seasonal variability in available food resources at the landscape level (Figure 3), but very little is known about the various mechanisms mediating these variations in movements. Without this mechanism-level understanding, it is difficult to predict how these patterns will change with environmental change.

Migrants must use local cues to tune their behaviour to remote conditions, and we expect natural selection to have shaped migration-decision mechanisms that use only the most reliable cues as input. Most migrant species likely time their departure from wintering grounds by responding to photoperiodic cues, but update their arrival time and destination with new information as they migrate. Birds and bats can update information when they pause at stopover sites to replenish energy stores, shelter or rest $[18,32,51,61-66]$, while fish and ungulates may migrate fairly steadily for months [67] and more gradually experience new and potentially more accurate information. As a bird during spring migration proceeds from one stopover to the next on its way north, ecological conditions at the breeding grounds may become more predictable, but even at the final stopover site, there may be little or no direct information on the conditions that await the migrant on its breeding ground [68]. Anthropogenic change may alter temporal and spatial patterns of resource distribution [69] or of associated cues [70], and can therefore diminish or enhance the fitness advantage of migration. Thus, photoperiodic cues that once reliably indicated timing of snow melt on the breeding grounds for Arctic-nesting geese, may come to be unreliable with rapid changes in the calendar of events in the high Arctic. This is particularly clear in the case of spring migrations, where many animals leave relatively stable low latitudes to reach suitable breeding grounds at higher latitudes where conditions are far more variable, even from one day to the next.

However, conditions at the remote target area are not the exclusive determinants of migratory success: the animal must prepare to migrate by adjusting its own physiological condition. For instance, a local weather phenomenon such as the arrival of rain may be a predictor of local grass and seed abundance essential to accumulate sufficient fuel for a long flight, and this may trigger processes such as moult or morphological changes in advance of the predicted accumulation of fat. Such local stimuli may thus be expected to interact with cues for remote conditions. The focal migrant may be in the company of a partner and several juveniles as a consequence of the previous year's successful breeding, or it may be alone, and these sorts of social cues may be an important aspect of local conditions [71]. Yet another set of cues is given by the internal state of the animal. An individual may be recovering from a lean winter or a bout of flu, or may be fat and healthy. We thus distinguish between three categories of cues, according to whether they give information about remote conditions, local conditions, or individual state. Notice that the first two are shared by other members of the population, public information, while the third category reflects individual variation and is private.

Because migratory animals make decisions based on cues at one place that must be at least partially correlated with conditions at another, and these correlations are being altered by changes in the spatial distribution of resources due to climate change [72], many are asking how migrating animals will cope with rapid environmental changes. A better prediction of responses to some of the many potential mismatches between cues and conditions being created by anthropogenic change requires a better understanding of cues and their predictive value.

How does the type and reliability of information available to the migrant influence its ability to respond to changing environments? Since at least the 1940's and the work of Brunswik [73], the ecological validity of cues has been recognized to be related to a cue's correlation with relevant environmental features. McNamara et al. [74] developed a general model based on this logic that explores the relation between a cue and the optimal timing of an important life-history activity.

This model quantifies the fitness loss for organisms failing to time behaviours optimally. It decomposes the immediate change in fitness resulting from environmental changes into a component that is due to changes in the 


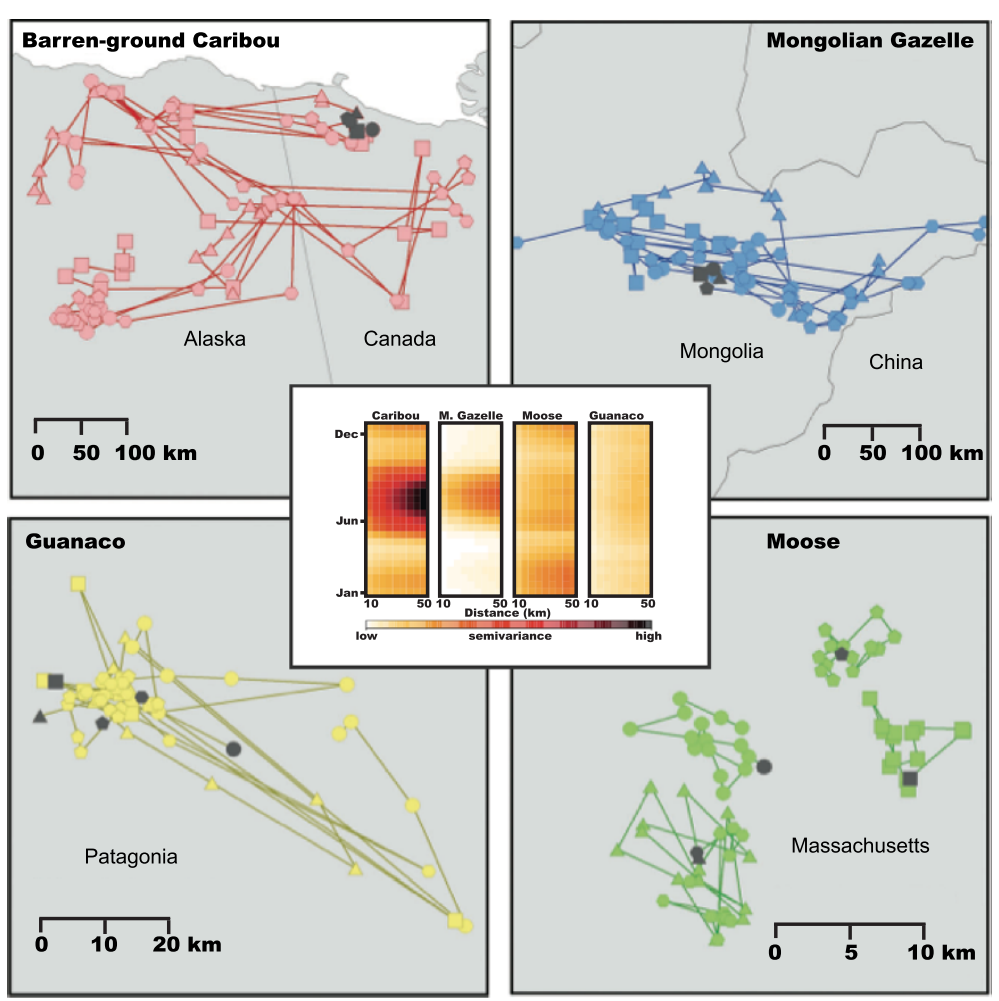

Figure 3 Examples of the variation in movement patterns of ungulates and how they relate to the seasonality of food availability. The different species have different scales and patterns of movements, and the timing and variability of movements is related to the seasonal variability (inset) in the vegetation in each habitat (adapted from Figures 1 and 5 in [60], which see for more details).

predictive power of the cue and another that derives from the mismatch of the old response to the cue from new environmental conditions. Here we illustrate this approach with examples based on the cues available to guide the timing of arrival on the breeding grounds, but similar approaches could be taken for many other sorts of migratory challenges in timing or location.

The ecological validity of cues needs to be couched in terms of fitness-decisive environments and outcomes (Figure 1). In the present example, these fitness outcomes can be summarized by the fact that, for any given year, we can assume that there is an optimal time, $T^{*}$, to arrive on the breeding grounds (Figure 4A). Across years, and across some range of years that the migrant's ancestors have faced, there has been a distribution of $T^{*}$, each $T^{*}$ being associated with a different value of the cue. This association between a cue and the optimal phenotype can be represented as a regression of $T^{*}$ on variation across years in the cue, and given sufficient time, the corresponding strategy of using the cue to decide optimal departure time could evolve as adaptive phenotypic plasticity. For a given range of cues, the slope of this regression gives us a measure of a cue's predictive power or information content: small changes in cue produce large differences in optimal behaviour (Figure 4B). By contrast, the variance or envelope around the regression gives us a measure of how accurate the cue is: a given cue value may be associated with a larger or smaller range of optimal times, depending on this variance (Figure $4 \mathrm{C}$ ). Note that, if the range in cue grows smaller, the slope with $T^{*}$ necessarily grows steeper (Figure 4D), likely resulting in selection for the organism to accurately discern smaller differences in the cue.

So far, we have assumed a constant relation between cues and environments, but these are likely to vary under global change. For example, if the endpoints of migration are warming faster than the areas where the decision to begin the migration is made, then individuals responding to the original cues would arrive too late (Figure 5A). Conversely, if the areas where the migration decision is made are warming faster, then optimal arrival time is unchanged but might now be predicted by a larger cue value, and an individual following the old cue-departure relationship would arrive too early (Figure 5B). In either case, a mismatch between actual arrival time and $T^{*}$ can result because the correlation between a cue and the distant environment has changed and the cue-response mechanism has not yet caught up. Individuals that use an old strategy will make errors in the new environments, until the 

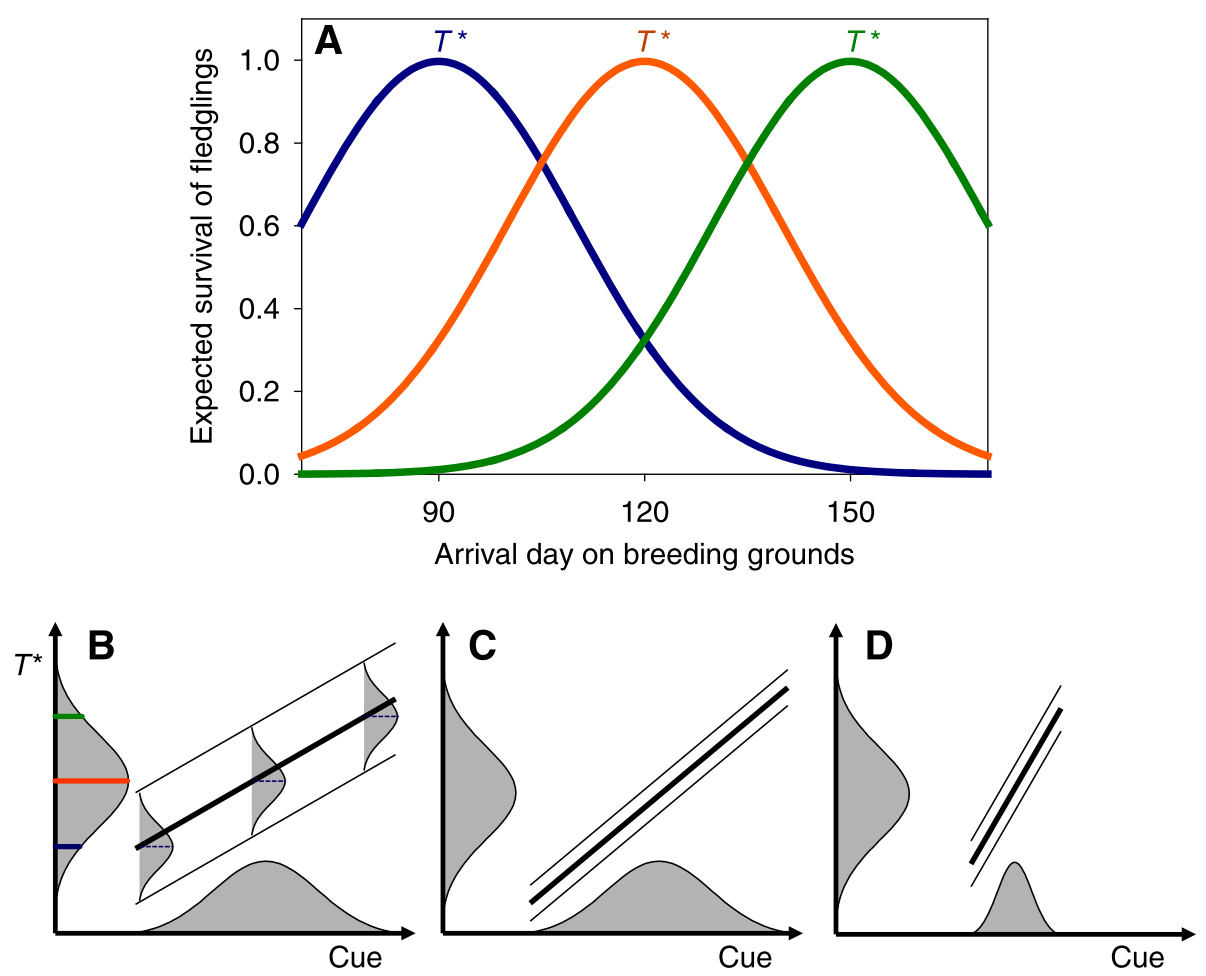

Figure 4 Fitness associated with a given arrival date at a breeding site varies in three different years. The peak in each year (A) denotes the optimal arrival date, $T^{*}$, and we assume that when many years are considered $T^{*}$ is normally distributed (shown along the $y$-axis in panels $\mathbf{B}$ through D). Bottom: B) The annual optimal arrival date may be predicted by a cue at a stopover or wintering site, with the between-year distribution of the cue shown as a normal distribution along the $x$-axis. The regression line shows the expected optimal arrival date for a given cue value, and the envelope indicates the uncertainty of the cue. C) Regressions on the cue can vary: in this case the cue provides more precise information (lower variance). D) If the distribution of the cue is narrower, there might be a larger cost of assessing the cue wrongly, and one could expect selection on individuals to estimate the cue better through enhanced perception, cognition, or increased sampling.

strategy has changed to reflect the new environmental correlations. Depending on the mechanism underlying the strategy, social learning, imprinting, or genetic evolution may be required for the population to keep up with the environmental change.

This simple model gives us a way to conceptualize various kinds of phenological mismatches between migratory schedules and changing environments. It provides a very simple way to envision the pressures on migrants to accurately detect fine changes in cue values and to imagine how selection could act in adjusting the pairing of strategies to cues or in shifting the decisions made by the migrants over to a different cue. This focus on the information available from the environment and how its value is constantly being assessed by selection becomes especially meaningful and intriguing when we remember that the environment of a migrating animal is a constantly shifting spectrum of cues of different sorts and reliabilities.

\section{Stopover sites as information sources}

One of the most interesting properties of migratory strategies is that they are timed along a spectrum of

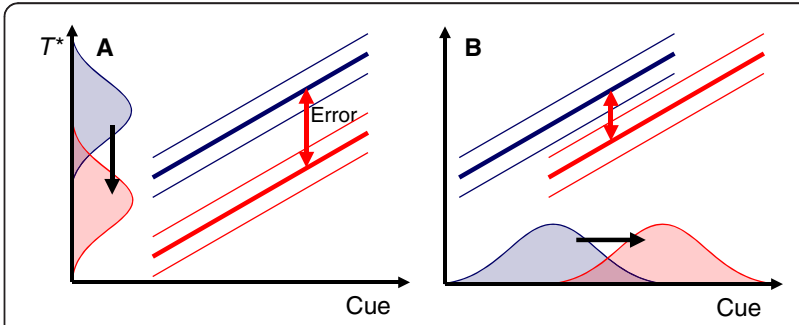

Figure 5 Two ways in which global change may cause mismatch between cue and optimal migration timing $\left(T^{*}\right)$. A) Conditions at the breeding grounds change from the blue to the red distribution so that $T^{*}$ is earlier than before. This implies that the optimal relationship prescribes earlier migration for a given cue (shift from blue to red relationship). Individuals that follow the old strategy (blue) arrive too late in the changed environment (red), and over time one would expect a change from the blue to the red strategy. B) The distribution of the cue changes in the area where the migration decision is made, but there is no change at the breeding grounds. Individuals with the old (blue) strategy now arrive too early. Again, a change from the blue to the red strategy over time would allow the migratory strategy to remain successful. 
environments along the migratory path. Migrants that use stopover sites may have to choose among possible areas that differ in the qualities of the cues available at each. The quality of information at a site may have as large a potential effect on fitness as other more traditional site characteristics such as food availability and predation risk. The information value of stopping over can be visualized in a simple graphical model (Figure 6). More accurate information gained from a stopover site might allow migrants to arrive at the breeding ground at a more appropriate time than the long-term mean best arrival time. The more variable conditions are at the breeding grounds from year to year, the more valuable this stopover information source is likely to be. Climate-related cues are probably correlated in space [75], and stopover sites closer to the breeding grounds are therefore likely to yield information that has higher predictive power about breeding conditions. A challenge for future research would be to quantify the information value of potential stopover sites and incorporate this with other more traditional ecological properties as important characteristics to be weighed in considering optimal migratory routes and timing. The need for such an assessment appears to be growing in the paradigmatic Pied Flycatcher system we will discuss next.

\section{When information at stopover sites grows less reliable}

Cues used in wintering (for migratory initiation) and stopover areas (for migratory pause and resumption) are likely to be different. Pied flycatchers (Ficedula hypoleuca) are small passerine birds, which, like most European migrants, spend the winter south of the Sahara in Africa, where local environmental conditions are not well correlated with those in the western European breeding grounds. Both and Visser [76] interpreted this poor information as being the basis for the bird's reliance on photoperiodic cues to time their spring departure from Africa. Changes in the response to photoperiodic cues were thought to require evolutionary adjustment and thus be much slower than the physiological changes in phenology exhibited by their insect prey on northern European breeding grounds. This was thought to explain a phenological mis-match in which the flycatchers were returning to their breeding grounds too late to take advantage of the earlier peak in insect food.

However, recent work [72] shows that from 1980 to 2005 pied flycatchers advanced their passage through northern Africa by two weeks (see also [77] for the same pattern in other species). This advance seems at variance with the lack of change in observed arrival further north in the United Kingdom, Netherlands and Germany [78,79], where the mismatch between breeding date and peak food abundance has only increased [80], leading to population declines $[81,82]$ and increased selective pressure for earlier breeding [74]. This paradox appears be resolved by considering conditions in the Iberian Peninsula and France, where temperatures during the period of the flycatchers' northward passage have not changed in parallel with those in northern Europe (Figure 7). Although birds are arriving earlier at the southern fringe of Europe, they appear to delay their subsequent departure and end up staying longer in these southern stopover areas.

This observation can be explained by two hypotheses, which may act in concert: (H1) the mismatch observed on the breeding grounds is due to deteriorating cue quality at the stopover site, or (H2) the birds are moving as fast as they can, and they are held up by poor feeding conditions at stopover sites. H1 suggests that the flycatchers are waiting somewhere south of the breeding grounds for warm weather, which, according to their strategy is interpreted as a signal for prime arrival conditions further north. The environmental correlation may have changed, but the strategy for migratory timing has not yet been updated to reflect those changes. In contrast, it is possible $(\mathrm{H} 2)$ that the flycatchers migrate north as fast as conditions allow, their flights not moderated by cues to conditions further north as they migrate. There could thus be no change in strategy, but the cold weather in the Iberian Peninsula and France would increasingly act as a constraint on the rate of feeding and delay the time it takes to amass the stores necessary to make the final leg of the journey north. While H1 suggests that flycatchers stay in Spain until the cues there tell them to leave, $\mathrm{H} 2$ suggests that they stay until the earliest date at which they can amass enough body stores to complete their migration. These hypotheses could be distinguished with observations of body condition of migrant flycatchers in Spain in early spring: are migrants very lean in Spain $(\mathrm{H} 2)$, or are they in good condition and waiting to continue until the cues in Spain tell them to go (H1)? An experimental test, with supplemental feeding of staging birds, might even be possible. In any event, support for $\mathrm{H} 1$ would serve as cogent evidence for both the information value of stopover sites and the dangers for accurate migration timing when the information available en route degrades in quality.

The flycatcher system also causes us to re-consider flexibility of the strategy these birds use to time migratory departure from the wintering grounds. Both and Visser [76] assumed the breeding season mismatch resulted from an evolutionary constraint: the change in departure time from the wintering grounds would require genetic selection and evolution, which would be slower than the physiological responses of their breeding-ground insect prey to changing temperatures. However, recent evidence shows that the cue-response to photoperiod in Africa need not rely on genetic adaptation [72]. Early-born flycatchers from the southern half of their breeding range 

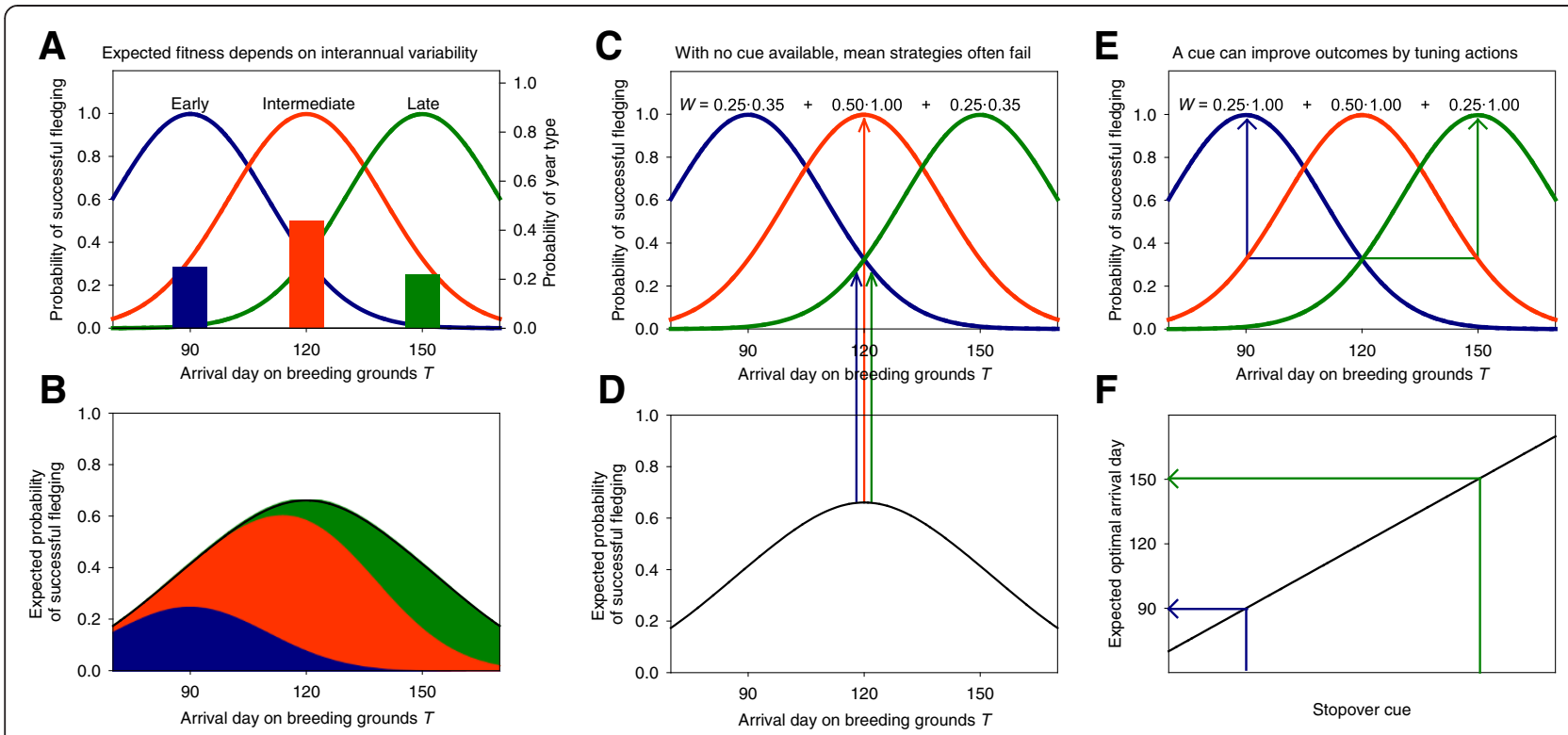

Stopover cue

Figure 6 Stopover-site information can fine-tune arrival at variable breeding grounds. LEFT: A) Expected breeding success depends on timing, with the peak of the curve indicating the optimal arrival time $T^{*}$. Environmental conditions vary between early, intermediate, and late years, with the probability of each year type given by the bars and the right-hand scale. B) The long-term expected fitness for a given arrival date is the probability that a certain year type occurs multiplied by the fledging success in that type of year. The probabilities for each year type are here laid above each other for each date, not superimposed. CENTRE: If no information available, then the best option is to arrive at the date that represents the peak of the long-term fitness curve (panel $\mathbf{D}$ ). In the most common intermediate years this is the best option (orange arrow in panel C), but in early or late years there is a considerable fitness loss (blue and green arrows). Fitness W is the achieved fitness in each year type, indicated by the arrow, weighted by the probability of occurrence of the year type from panel A. RIGHT: Cues at a stopover site can guide arrival on breeding grounds at more appropriate times for each breeding season. In the cue-response (panel F), a cue that can be observed at the stopover site predicts what type of year it is and thus the optimal timing of migration. A low cue value from F) indicates an early year (blue line), and, compared to the situation where information is ignored, a higher fitness can be obtained in early years (blue arrow in panel E). Conversely, with late years (in green). The value of stopover-site information is the increased fitness in early and late years in panel $\mathbf{E}$ vs. C.

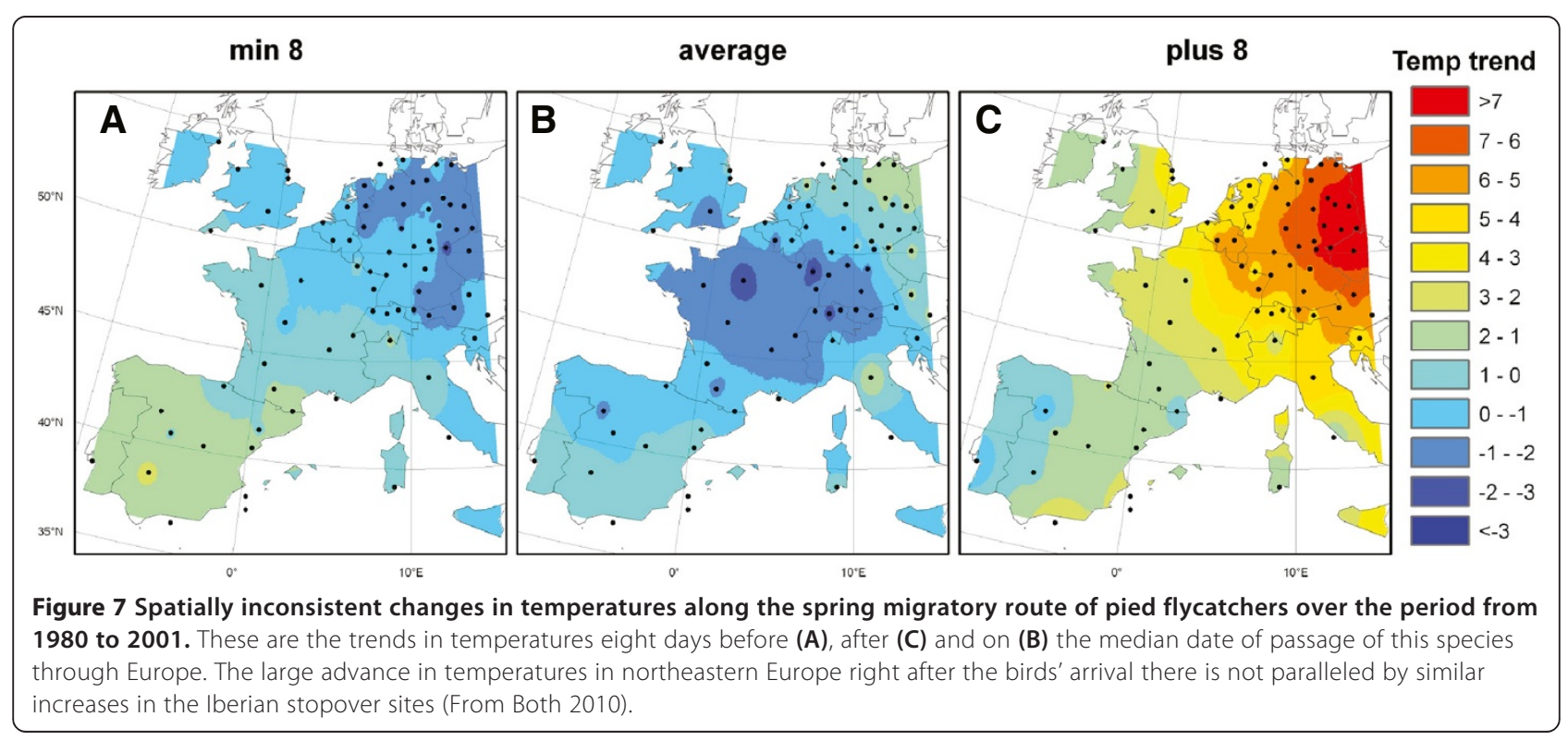


have been recovered earlier during spring migration in Northern Africa, whereas early-born individuals from the northern range have been recovered later at the same migratory stopovers (Figure 8). This intriguing pattern could be explained by the distinctive photoperiod dynamics experienced by young across this species' large latitudinal breeding range: nestlings fledging in longer days in the south, before the Solstice, may migrate north later in the following spring, whereas more northern young fledged after the Solstice experience shorter day-lengths when fledging later, and hence may initiate spring migration earlier. This may be an extension across the winter period of a photoperiodic flexibility first suggested between daylengths experienced by nestlings and the timing of their first autumn migration [83]. This suggests that departures from the wintering grounds are regulated by biological clocks that are calibrated phenotypically early in ontogeny. If so, adjustments of the migratory clock do not need to wait for genetic change.

\section{Cues, flexibility and information ecology}

Given the great variety of variable environments to which migrants' paths and schedules have been adjusted $[60,75]$, it would be surprising indeed if a great diversity of cues were not involved. Yet, precise identification of the cues used is very difficult. Wildebeest in the Serengetti respond to local variation in the protein content of their grass forage in their local movements. They apparently would not engage in their long-distance migrations, however, if they were not able to monitor and respond to rainfall conditions on the order of a hundred kilometers away [59]. Do they smell distantly greening landscapes, or is the sight and sound of persistent distant thunderstorms enough to cue them into the time to move?

We know a little more about movements of ducks (Anas spp.) in Australia that respond to distant weather cues over 100s of kilometers [84] and have been tracked over 1000 s of kilometers annually [48]. In this nonperiodic wet-dry system, the timing of peak resource abundance is irregular and patchily distributed, and thus, photoperiod provides almost no useful information for timing movements. There is strong evidence that the movement of many species in this system is cued to weather [85]. Nonetheless, the movements of waterfowl in Australia and in the similar landscapes of southern Africa are highly individualistic, suggesting that internal cues for guiding movement are at least as important as external cues such as rainfall $[48,86]$. There also appears to be a great deal of variability among shorebird species in the use of distant cues. Black-tailed Godwits (L. l. limosa) may use bad weather in their Spanish wintering grounds, which is correlated with wintry weather in the Netherlands, to cue a delay of their migratory departure from Spain [52].

Whatever is cuing waterfowl and shorebirds into the availability of resources at distance, the same ability to detect water conditions from afar is apparently lacking in Snail Kites (Rostrhamus sociabilis) in Florida. These birds are dependent on snail populations in wetlands that are seasonally and spatially variable. The birds apparently wander most widely when waters are generally high and feeding conditions are good [87], and perhaps information acquired in this way could help in part to explain the higher survival rates of adults compared to those of the inexperienced and uninformed juveniles when droughts dramatically reduce food availability [88]. If the birds are indeed wandering more widely during times of plenty, then future research might evaluate the possibility that the information yield of this wandering is a big part of its advantageousness.

The diversity of migratory types encountered in vertebrates $[14,75,89]$ suggests a spectrum of flexibility: at one end of this spectrum there may be obligate migrants that respond to few cues in a low-variance way. On the other end are facultative migrants (the most flexible of which

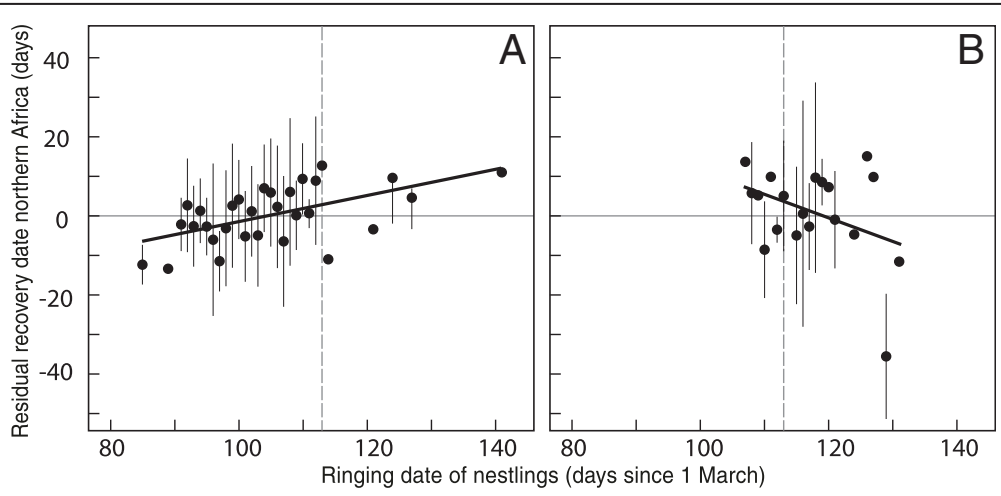

Figure 8 The effect of natal ringing date on the dates of capture in northern Africa during northward spring migration for Pied Flycatchers from nests south of (A) and north of (B) $57^{\circ} \mathrm{N}$ latitude, which corresponds roughly to lower European vs. Scandinavian localities, respectively. Ringing date relates directly to the date of fledging, and it is clear that birds have different responses to date in the two regions. The vertical dashed line is the date of the Solstice in each, and the points for each date are the means +/- 1 SD (From Both 2010). 
may well include "nomads" [75]) that respond to a variety of cues in a nuanced and flexible way.

Paradoxically, the obligate migrants, whose migratory cue-processing and decision-making machinery appear to have been most highly evolved for migration, may be those that will have the hardest time keeping up with rapidly changing global habitats and phenologies associated with anthropogenic climate change.

Why would any organism be selected for an obligate, few-cue, migration strategy? The answer appears to be in information availability. Facultative migration strategies are advantageous only as long as reliable environmental cues to guide migration remain available. When organisms have no reliable cues available, the only recourse is to rely on the long-term mean date or direction that has been selectively favoured over generations. The model and figures above, as well as other recent work (e.g. [75]) suggests a valuable way to begin to understand the reliability of any given cue as predictor of conditions somewhere else, but much more needs to be done on this topic.

Ultimately though, organisms will only continue to pursue a migratory path as long as environmental conditions along that path provide sufficient resources to sustain migration.

In any event, it is important to add "information" to the important attributes necessary for successful migration (Figure 6): reliable information makes efficient scheduling and routing possible. Though it is not clear how demanding information processing and decision-making are, a serviceable null hypothesis would be that even the most apparently obligate, hard-wired species retain flexibility and the ability to respond to environmental cues when they are reliable and perceptible. Thus, if north temperate ducks retain the same sensory capabilities as their relatives in the Southern Hemisphere (e.g. [90]), it may be that the regularity in the timing of movements that they display arises from the regular seasonality of their habitats not a hard-wired adherence to a photoperiodic cue.

Much is known of the cues used by migrating fish to navigate at sea $[16,17]$, and the list of cues used (magnetic fields, solar compass, etc.) is remarkably similar to that used by birds. This reinforces the commonality among all vertebrates in the possession of a default generic set of sensory capacities that make long-distance return migrations sustainable. Most of these sensory capacities in all vertebrates have been explored most intensively in the context of orientation and making spatial decisions. But we suggest that there are three valuable research directions before us:

1) An evaluation of this common vertebrate tool kit, its phylogenetic distribution, and how often the same sensory modalities are being used to guide migration in all vertebrate (and invertebrate?) groups, 2) An expanded scope in studies of vertebrate sensory systems to explore their use for generating cues for timing movements and life history changes, and 3) The use of broad sensory capabilities as a null hypothesis for vertebrates, one consequence of which would be that low-variance patterns in movements be explored as response to low-variance environments.

\section{Conclusions}

Bringing strategies and information together in an era of rapid global change

All the examples in this review demonstrate the key importance of the mechanisms behind variation in migratory behaviour. It is far too easy to assume that the behavioural differences we see between individuals or species reflect directly their migratory strategies and information-processing machinery. Even obligate migrants may retain considerable information-gathering capacity, even if their environments provide few reliable or meaningful local cues. If this lack of valuable environmental information persists, an obligate migrant will be selected for earlier or later departure times as conditions change. As long as some individuals are surviving along the migratory path, and the underlying genetic causation is sufficiently simple and direct, selection will constantly fine-tune the timing of the migrant to produce the best long-term migratory departure times. It is not at all clear how many major genes are involved in variation in migratory strategies [see [91,92] for the very beginnings of an answer], but the number is likely to be large or with many pleiotropic effects. These sorts of traits are not likely to respond very rapidly to directional selection, though much depends on how the phenotypic plasticity is coded and inherited [93]. We suspect that few, if any, migratory systems are as simple as this. Most migratory strategies appear to respond to a complicated set of cues, often redundant, and these strategies have been selectively honed for many millions of years to make favourable migration decisions in the face of variable cues, the reliabilities of which have likely been changing constantly.

In addition, the work on Pied Flycatchers (Figure 8) suggesting effects of photoperiod in the nest on the timing of migratory departure on the first spring migration north from Africa indicates that there may well be mechanisms built into migratory strategies that allow migrants to adjust their response mechanisms according to their own developmental histories and experiences. Years ago, Emlen [94] showed that nocturnal, star-navigating migrants learned the direction for migration from the relative rotation of stars in the night sky, not from any fixed "map" of the stars' positions. In a similar way, the effect of natal photoperiod on subsequent migratory timing may be the result of an overarching mechanism for migratory flexibility and re-programming. This work suggests higher-order mechanisms for adjusting the cue- 
response machinery at the center of migratory decision making. These mechanisms could be simple and robust means for tuning the migratory decision-making machine that would produce very serviceable migration calendars without the need for fine-tuned selection in any new area that dispersing birds colonized, and there is a fascinating challenge to begin to explore the evolution of mechanisms of decision-making at all levels as well as the decisions themselves [53]. Many migrants show an uncanny ability to make reasonable decisions in guiding their migrations $[95,96]$, and before predicting an inability to cope with the rapid pace of environmental change, we need to better understand the scope and nature of the response mechanisms involved.

The most interesting (and difficult) challenge raised by considering both the biology of migrants and the patterns of cue-correlations in their environments is whether constraints in patterns of movement along a potential migratory path rest in the organisms themselves or in their environments. We have already seen that Black-tailed Godwits appear to be good at responding to cues at staging areas to fine-tune their migratory phenology. By contrast, birds in one population of Bar-tailed Godwit, L. lapponica, make the longest non-stop journey known in any terrestrial vertebrate, a trans-Pacific migration from Alaska to New Zealand $[97,98]$. These Alaskan bar-tailed godwits presumably have little information available to them about the precise conditions in New Zealand when they depart, instead being able to rely on local conditions only as an indicator of flight conditions for the early part of their route [96]. How much would conditions in the Pacific have to change to make the trans-oceanic flight no longer feasible even for these godwits? Could godwits today manage a flight that was 5 or 10\% longer than they currently endure? Their capacity for change will eventually reach a limit imposed by physics and metabolic physiology, but this would be a different limit than that faced by most birds. When conditions change rapidly, the viability of migratory paths is determined by the ability of any migrants to survive the journey, and if none can make it, the path is not viable and there will clearly not be selection to improve performance along that path. The migrants using that path will cease doing so and find another path or perish.

Recall that Red Knots (Calidris canutus) and Blacktailed Godwits follow a very similar path from Africa to northwestern Europe, but use different strategies to do so. Red Knots seem to use a fixed and narrow time window of departures on a non-stop flight, only making an 'emergency' stopover on the French Atlantic coast $[99,100]$ if forced to do so by difficult wind conditions en route. This contrasts with the godwits, which take the same journey in at least two hops, assessing the situation before proceeding from the staging areas along the way.
Why would such similar animals have such different strategies? Is it because they actually use different microhabitats (non-tidal flooded fields such as rice fields, marshes and mud for the godwit; intertidal open mudflats for the Red Knot) that vary dramatically in their predictability or availability along the migratory route? Or is it because Red Knots are specialist mollusc feeders $[101,102]$ that need to resorb much of their large muscular gizzard (to save weight before taking a long flight) and re-build it again at every staging area (to efficiently feed and re-fuel [103]). By contrast, the godwits have no such internal body re-organisation necessary to stop and forage or to take off on a flight. This contrast between the constraints of environments vs. organismal performance is a rich ground for investigations in the interaction of ecology and physiology.

Making predictions of migrant responses to environmental changes clearly requires a better understanding of the strategies being used by migrants and how the expression of those strategies interacts with internal and external state variables to produce variable outcomes, each of which has different implications for fitness. The availability and reliability of information are critical at the evolutionary scale (in affecting the fitness of facultative vs. obligate strategies) and at the proximate level (in affecting the reliability of changing cues available during migration). And the interactions of sensory and cognitive systems with other organ systems in producing integrated migrant phenotypes are an intriguing frontier for biological research.

Of course, biologists can argue that we need a similar more-thorough understanding of any phenotypically variable trait, but migrants are especially compelling in this regard. They are constantly faced with decisions that have dramatically different costs and potential benefits, many of which can have uncommonly immediate fitness consequences. Working to better understand the control of migration can serve as a laboratory of extremes that may help us anticipate environmental problems for these fascinating creatures at the same time that it should help us understand the causes and effects that underlie less extreme phenotypic variations throughout biology.

\section{Competing interests}

The authors declare that they have no competing interests.

\section{Authors' contributions}

DW and TP co-led the workshop, attended by $C J, A H, J M, D L, J P$, and $A F$, that catalyzed these ideas; DW led the drafting and preparation of the MS; CJ prepared the original figures; and all the above plus CB, AK, and DR actively participated in the preparation and revision of the manuscript. All authors read and approved the final manuscript.

\section{Acknowledgements}

We thank the MIGRATE-RCN supported by the US NSF, and coordinators Jeff Kelly and Sarah Mabey, for convening the Hegne meeting, ably organized by a team from the Max Planck Institute of Ornithology (Martin Wikelski et al.). DWW was supported by program support funds from Cornell University and 
by NSF grants DEB-0717021, IOS-0744753 and OISE-0730180; CJ acknowledges funding from the Research Council of Norway; AlH was supported by the European Research Council (Advanced Grant 250209); JP has been supported by the Volkswagen Foundation (Evolutionary Biology Initiative); DR was supported by NIH grant HHSN266200700010C; TP has been supported by a PIONIER-grant in 1996-2002, operational grants from NIOZ and RUG in 2002-2012, an NWO-ALW TOP-grant (Shorebirds in space) in 2011-2015, and a grant from the Netherlands Waddenfonds (Metawad, WF209925).

\section{Author details}

'Department of Ecology and Evolutionary Biology, Corson Hall, Cornell University, Ithaca, NY 14853, USA. ${ }^{2}$ Cornell Museum of Vertebrates \& Laboratory of Ornithology, 159 Sapsucker Woods Road, Ithaca, NY 14850, USA. ${ }^{3}$ Uni Research and Hjort Centre for Marine Ecosystem Dynamics, P.O. Box 7810, N-5020 Bergen, Norway. ${ }^{4}$ Animal Ecology Group, Centre for Ecological and Evolutionary Studies, University of Groningen, P.O. Box 11103, 9700 CC Groningen, The Netherlands. ${ }^{5}$ School of Biological Sciences, University of Bristol, Bristol BS8 1UG, UK. ${ }^{6}$ School of Mathematics, University of Bristol, Bristol BS8 1TW, UK. ${ }^{7}$ National Science Foundation, Arlington, VA 22230, USA. ${ }^{8}$ Max Planck Institute for Ornithology, Vogelwarte Radolfzell, Am Obstberg 1, 78315 Radolfzell, Germany. ${ }^{9}$ Department of Biology, University of Konstanz, 78457 Constanz, Germany. ${ }^{10}$ Current address: Department of Biology, Jordan Hall, Indiana University, Bloomington, IN 47405, USA. ${ }^{11}$ Behavioural Ecology Research Group, Department of Zoology, Oxford University, Oxford OX1 3PS, UK. ${ }^{12}$ Australian Wildlife Conservancy, P.O. Box 6621, Adelaide SA 5000, Australia. ${ }^{13}$ Department of Marine Ecology, NIOZ Royal Netherlands Institute for Sea Research, P.O. Box 58, 1790 AB Den Burg, Texel, The Netherlands.

\section{Received: 25 December 2013 Accepted: 16 May 2014}

Published: 29 May 2014

\section{References}

1. Huntley B: How plants respond to climate change - migration rates, individualism and the consequences for plant-communities. Ann Bot 1991, 67:15-22.

2. Parmesan C: Ecological and evolutionary responses to recent climate change. Annu Rev Ecol Evol Syst 2006, 37:637-669.

3. Thomas CD, Hill JK, Anderson BJ, Baily S, Beale CM, Bradbury RB, Bulman CR, Crick HQP, Eigenbrod F, Griffiths HM, Kunin WE, Oliver TH, Walmsley CA, Watts K, Worsfold NT, Yardley T: A framework for assessing threats and benefits to species responding to climate change. Methods Ecol Evol 2011, 2:125-142.

4. Burrows MT, Schoeman DS, Buckley LB, Moore P, Poloczanska ES, Brander KM, Brown C, Bruno JF, Duarte CM, Halpern BS, Holding J, Kappel CV, Kiessling W, O'Connor MI, Pandolfi JM, Parmesan C, Schwing FB, Sydeman WJ, Richardson AJ: The pace of shifting climate in marine and terrestrial ecosystems. Science 2011, 334:652-655.

5. Hodgson JA, Thomas CD, Wintle BA, Moilanen A: Climate change, connectivity and conservation decision making: back to basics. J App/ Ecol 2009, 46:964-969.

6. Møller AP, Fiedler W, Berthold P: Effects of Climate Change on Birds. Oxford: Oxford University Press; 2010

7. Piersma T: Using the power of comparison to explain habitat use and migration strategies of shorebirds worldwide. J Ornithol 2007 148(Suppl 1):S45-S59.

8. Amano T, Székely T, Koyama K, Amano H, Sutherland WJ: A framework for monitoring the status of populations: an example from wader populations in the East Asian- Australasian flyway. Biol Conserv 2010, 143:2238-2247.

9. Both C, Van Turnhout CAM, Bijlsma RG, Siepel H, Van Strien AJV, Foppen RPB: Avian population consequences of climate change are most severe for long-distance migrants in seasonal habitats. Proc R Soc Lond Ser B 2010, 277:1259-1266.

10. van Turnhout CAM, Foppen RPB, Leuven RSEW, Van Strien A, Siepel H: Life-history and ecological correlates of population change in dutch breeding birds. Biol Conserv 2010, 143:173-181.

11. Yang H-Y, Chen B, Barter M, Piersma T, Zhou C-F, Li F-S, Zhang Z-W: Impacts of tidal land reclamation in Bohai Bay, China: ongoing losses of critical Yellow Sea waterbird staging and wintering sites. Bird Conserv Int 2011, 21:241-259.
12. Sherwin HA, Montgomery WI, Lundy MG: The impact and implications of climate change for bats. Mammal Rev 2013, 43:171-182.

13. Okunishi T, Ito SI, Hashioka T, Sakamoto TT, Yoshie N, Sumata H, Yara Y, Okada N, Yamanaka Y: Impacts of climate change on growth, migration and recruitment success of Japanese sardine (Sardinops melanostictus) in the western North Pacific. Clim Chang 2012, 115:485-503.

14. Dingle H: Migration. The Biology of Life on the Move. Oxford: Oxford University Press; 1996.

15. Newton I: The Migration Ecology of Birds. New York: Academic; 2010.

16. MacKeown BA: Fish Migration. London: Croom Helm; 1984.

17. MacCleave JD, Arnold GP, Dodson JJ, Neil WH: Mechanisms of Migration in Fishes. New York: Plenum; 1984

18. Fleming TH, Eby P: Ecology of bat Migration. In Bat ecology. Edited by Kunz TH, Fenton MB. Chicago: University of Chicago Press; 2003:156-208.

19. Piersma T, Pérez-Tris J, Mouritsen H, Bauchinger U, Bairlein F: Is there a "migratory syndrome" common to all migrant birds? Ann N Y Acad Sci 2005, 1046:282-293.

20. Carroll SP, Hendry AP, Reznick DN, Fox CW: Evolution on ecological time-scales. Funct Ecol 2007, 21:387-393.

21. Hairston NG, Ellner SP, Geber MA, Yoshida T, Fox TA: Rapid evolution and the convergence of ecological and evolutionary time. Ecol Lett 2005, 8:1114-1127.

22. Pelletier F, Clutton-Brock T, Pemberton J, Tuljapurkar S, Coulson T: The evolutionary demography of ecological change: linking trait variation and population growth. Science 2007, 315:1571-1574.

23. Berthold P, Helbig AJ, Mohr G, Querner U: Rapid microevolution of migratory behaviour in a wild bird species. Nature 1992, 360:668-670.

24. Pulido F, Berthold P: Current selection for lower migratory activity will drive the evolution of residency in a migratory bird population. Proc Natl Acad Sci U S A 2010, 107:7341-7346.

25. Dragesund $\mathrm{O}$, Johannessen $\mathrm{A}, \mathrm{U}$ lltang $\varnothing$ : Variation in migration and abundance of Norwegian spring spawning herring (Clupea harengus L). Sarsia 1997, 82:97-105.

26. Huse $G$, Railsback $S$, Fernö $A$ : Modelling changes in migration pattern of herring: collective behaviour and numerical domination. J Fish Biol 2002, 60:571-582.

27. Piersma T, van Gils JA: The Flexible Phenotype. A Body-centred Integration of Ecology, Physiology, and Behaviour. Oxford: Oxford University Press; 2011.

28. Piersma T: Flyway evolution is too fast to be explained by the modern synthesis: proposals for an 'extended' evolutionary research agenda. J Ornithol 2011, 152(Suppl 1):S151-S159.

29. Brodersen J, Nilsson PA, Chapman BB, Skov C, Hansson LA, Brönmark C: Variable individual consistency in timing and destination of winter migrating fish. Biol Lett 2012, 8:21-23.

30. van Noordwijk AJ, Müller CB: On Adaptive Plasticity in Reproductive Traits, Illustrated with Laydate in the Great Tit and Colony Inception in a Bumble Bee. In Animal Societies; Individuals, Interactions and Organisation. Edited by Jarman PJ, Rossiter A. Kyoto: Kyoto University Press; 1994:180-194.

31. Piersma T, Drent J: Phenotypic flexibility and the evolution of organismal design. Trends Ecol Evol 2003, 18:228-233.

32. Gudmundsson GA, Lindström $\AA$, Alerstam T: Optimal fat loads and longdistance flights by migrating knots Calidris canutus, sanderlings Calidris alba and turnstones Arenaria interpres. Ibis 1991, 133:140-152.

33. Alerstam T, Lindström Å: Optimal Bird Migration: The Relative Importance of Time, Energy and Safety. In Bird Migration: Physiology and Ecophysiology. Edited by Gwinner E. Berlin: Springer; 1990.

34. Weber TP, Houston Al, Ens BJ: Optimal departure fat loads and stopover site use in avian migration - an analytical model. Proc R Soc Lond B 1994 258:29-34.

35. Hedenstrom A, Alerstam T: Optimum fuel loads in migratory birds: distinguishing between time and energy minimization. J Theor Biol 1997, 189:227-234.

36. Weber TP, Hedenstrom A: Long-distance migrants as a model system of structural and physiological plasticity. Evol Ecol Res 2001, 3:255-271.

37. Barta Z, McNamara JM, Houston Al, Weber TP, Hedenström A, Feró O: Optimal moult strategies in migratory birds. Philosophical Trans Royal SoC B-Biol Sci 2008, 363:211-229.

38. Houston Al, McNamara JM: Models of Adaptive Behaviour: an Approach Based on State. Cambridge: Cambridge University Press; 1999. 
39. Houston Al, McNamara JM: Phenotypic plasticity as a state-dependent life-history decision. Evol Ecol 1992, 6:243-253.

40. McNamara JM, Welham RK, Houston Al: The timing of migration within the context of an annual routine. J Avian Biol 1998, 29:416-423.

41. Weber TP, Ens BJ, Houston Al: Optimal avian migration: a dynamic model of fuel stores and site use. Evol Ecol 1998, 12:377-401.

42. Weber TP, Houston Al, Ens BJ: Consequences of habitat loss at migratory stopover sites: a theoretical investigation. J Avian Biol 1999, 30:416-426.

43. Purcell J, Brodin A: Factors influencing route choice by avian migrants: a dynamic programming model of Pacific brant migration. J Theor Biol 2007, 249:804-816.

44. Bauer S, Ens BJ, Klaassen M: Many routes lead to Rome: potential causes for the multi- route migration system of Red Knots, Calidris canutus islandica. Ecology 2010, 91:1822-1831.

45. Jørgensen C, Dunlop ES, Opdal AF, Fiksen $\varnothing$ : The evolution of spawning migrations: state dependence and fishing-induced changes. Ecology 2008, 89:3436-3448.

46. Jonker RM, Eichhorn G, van Langevelde F, Bauer S: Predation danger can explain changes in timing of migration: the case of the Barnacle Goose. PLoS One 2010, 5:e11369.

47. Houston Al: Models of optimal avian migration: state, time and predation. J Avian Biol 1998, 29:395-404.

48. Roshier DA, Doerr VAJ, Doerr ED: Animal movement in dynamic landscapes: interaction between behavioural strategies and resource distributions. Oecologia 2008, 156:465-477.

49. Zbinden JA, Bearhop S, Bradshaw P, Gill B, Margaritoulis D, Newton J, Godley BJ: Migratory dichotomy and associated phenotypic variation in marine turtles revealed by satellite tracking and stable isotope analysis. Mar Ecol Prog Ser 2011, 421:291-302.

50. van Noordwijk AJ, Pulido F, Helm B, Coppack T, Delingat J, Dingle $H_{\text {, }}$ Hedenström A, van der Jeugd H, Marchetti C, Nilsson A, Pérez-Tris J: A framework for the study of genetic variation in migratory behaviour. J Ornithol 2006, 147:221-233.

51. Conklin JR, Battley PF, Potter MA, Fox JW: Breeding latitude drives individual schedules in a trans-hemispheric migrant bird. Nat Commun 2010, 1:67.

52. Lourenço PM, Kentie R, Schroeder J, Groen NM, Hooijmeijer JCEW, Piersma $\mathrm{T}$ : Repeatable timing of northward departure, arrival and breeding in black-tailed godwits Limosa I. limosa, but no domino effects. J Ornithol 2011, 152:1023-1032.

53. McNamara JM, Houston Al: Integrating function and mechanism. Trends Ecol Evol 2009, 24:670-675

54. Sutherland WJ: Evidence for flexibility and constraint in migration systems. J Avian Biol 1998, 29:441-446.

55. Quinn TP, Dittman AH: Pacific salmon migrations and homing - mechanisms and adaptive significance. Trends Ecol Evol 1990, 5:174-177.

56. Perdeck AC: Orientation of starlings after displacement to Spain. Ardea 1967, 55:194-202.

57. Perdeck AC: An experiment on the orientation of juvenile starlings during spring migration. Ardea 1974, 62:190-195.

58. Thorup K, Bisson I-A, Bowlin M, Holland RA, Wingfield JC, Ramenofsky M, Wikelski M: Evidence for a navigational map stretching across the continental US in a migratory songbird. Proc Natl Acad Sci U S A 2007, 104:18115-18119.

59. Holdo RM, Holt RD, Fryxell JM: Opposing rainfall and plant nutritional gradients best explain the wildebeest migration in the Serengeti. Am Nat 2009, 173:431-445.

60. Mueller T, Olson KA, Dressler G, Leimgruber P, Fuller TK, Nicolson C, Novaro AJ, Bolgeri MJ, Wattles D, DeStefano S, Calabrese JM, Fagan WF: How landscape dynamics link individual- to population-level movement patterns: a multispecies comparison of ungulate relocation data. Glob Ecol Biogeogr 2011, 20:683-694.

61. Piersma T, Rogers DJ, González PM, Zwarts L, Niles LJ, De Lima Serrano Do Nascimento I, Minton CDT, Baker AJ: Fuel storage rates before northward flights in Red Knots worldwide: facing the severest ecological constraint in tropical intertidal environments? In Birds of Two Worlds: The Ecology and Evolution of Migration. Edited by Greenberg R, Marra PP. Baltimore: Johns Hopkins University Press; 2005:262-273.

62. Voigt CC, Sörgel K, Šuba J, Keišs O, Pētersons G: The insectivorous bat Pipistrellus nathusii uses a mixed-fuel strategy to power autumn migration. Proc Royal Soc B: Biol Sci 2012, 279:3772-3778.
63. Sawyer $\mathrm{H}$, Kauffman MJ: Stopover ecology of a migratory ungulate. J Anim Ecol 2011, 80:1078-1087.

64. Sawyer H, Kauffman MJ, Middleton AD, Morrison TA, Nielson RM, Wyckoff TB: A framework for understanding semi-permeable barrier effects on migratory ungulates. J App/ Ecol 2013, 50:68-78.

65. McGuire LP, Guglielmo CG, Mackenzie SA, Taylor PD: Migratory stopover in the long-distance migrant silver-haired bat, Lasionycteris noctivagans. J Anim Ecol 2012, 81:377-385.

66. Forestell PH, Kaufman GD, Chaloupka M: Long-term trends in abundance of humpback whales in Hervey Bay, Australia. J Cetacean Res Manag 2011, 3:237-241.

67. Aarestrup K, Økland F, Hansen MM, Righton D, Gargan P, Castonguay M, Bernatchez L, Howey P, Sparholt H, Pedersen MI, McKinley RS: Oceanic spawning migration of the european eel (Anguilla anguilla). Science 2009, 325:1660.

68. Senner NR: One species but two patterns: Populations of Hudsonian Godwits (Limosa haemastica) differ in spring migration timing. Auk 2012, 129:670-682.

69. Both $C$, te Marvelde L: Climate change and timing of avian breeding and migration throughout Europe. Clim Res 2007, 35:93-105.

70. Bauer S, Nolet BA, Giske J, Chapman JW, Akesson S, Hedenstrom A, Fryxell JM: Cues and Decision Rules in Animal Migration. In Animal Migration: A Synthesis. Edited by Milner-Gulland EJ, Fryxell JM, Sinclair ARE. Oxford: Oxford University Press; 2011:68-87.

71. Helm B, Piersma T, van der Jeugd HP: Sociable schedules: interplay between avian seasonal and social behaviour. Anim Behav 2006, 72:245-262.

72. Both C: Flexibility of timing of avian migration to climate change masked by environmental constraints en route. Curr Biol 2010, 20:243-248.

73. Brunswik E: Organismic achievement and environmental probability. Psychol Rev 1943, 50:255-272.

74. McNamara JM, Barta Z, Klaassen M, Bauer S: Cues and the optimal timing of activities under environmental changes. Ecol Lett 2011, 14:1183-1190.

75. Jonzén N, Knudsen E, Holt RD, Saether B-E: Uncertainty and Predictability: The Niches of Migrants and Nomads. In Animal Migration: A Synthesis. Edited by Milner-Gulland EJ, Fryxell JM, Sinclair ARE. Oxford, UK: Oxford University Press; 2011:91-109.

76. Both C, Visser ME: Adjustment to climate change is constrained by arrival date in a long- distance migrant bird. Nature 2001, 411:296-298.

77. Jonzén N, Lindén A, Ergon T, Knudsen E, Vik JO: Rapid advance of spring arrival dates in long-distance migratory birds. Science 2006, 312:1959-1961.

78. Both C, Bijlsma RG, Visser ME: Climatic effects on timing of spring migration and breeding in a long-distance migrant, the Pied Flycatcher Ficedula hypoleuca. J Avian Biol 2005, 36:368-373.

79. Hüppop O, Winkel W: Climate change and timing of spring migration in the long-distance migrant Ficedula hypoleuca in central Europe: the role of spatially different temperature changes along migration routes. J Ornithol 2006, 147:326-343.

80. Both $C$, van Asch M, Bijlsma RG, van den Burg AB, Visser ME: Climate change and unequal phenological changes across four trophic levels: constraints or adaptations? J Anim Ecol 2009, 78:73-83.

81. Both C, Bouwhuis S, Lessells CM, Visser ME: Climate change and population declines in a long distance migratory bird. Nature 2006, 441:81-83.

82. Møller AP, Rubolini D, Lehikoinen E: Populations of migratory bird species that did not show a phenological response to climate change are declining. Proc Natl Acad Sci U S A 2008, 105:16195-16200.

83. Coppack T, Pulido F: Photoperiodic response and the adaptability of avian life cycles to environmental change. Adv Ecol Res 2004, 35:131-150.

84. Roshier DA, Asmus M, Klaassen M: What drives long-distance movements in the nomadic Grey Teal Anas gracilis in Australia? Ibis 2008, 150:474-484.

85. Reside AE, Van Der Wal JJ, Kutt AS, Perkins GC: Weather, not climate, defines distributions of vagile bird species. PLoS One 2010, 5:e13569.

86. Cumming GS, Gaidet N, Ndlovu M: Towards a unification of movement ecology and biogeography: conceptual framework and a case study on Afrotropical ducks. J Biogeogr 2012, 39:1401-1411.

87. Bennetts RE, Kitchens WM: Factors influencing movement probabilities of a nomadic food specialist: proximate foraging benefits or ultimate gains from exploration? Oikos 2000, 91:459-467. 
88. Martin J, Nichols JD, Kitchens WM, Hines JE: Multiscale patterns of movement in fragmented landscapes and consequences on demography of the Snail Kite in Florida. J Anim Ecol 2006, 75:527-539.

89. Winkler DW: How do Migration and Dispersal Interact? In Birds of Two Worlds: The Ecology and Evolution of Migration. Edited by Greenberg R, Marra PP. Baltimore: Johns Hopkins University Press; 2005:401-413.

90. Oppel S, Powell AN, Dickson DL: Using an algorithmic model to reveal individually variable movement decisions in a wintering sea duck. J Anim Ecol 2009, 78:524-531.

91. Mueller JC, Pulido F, Kempenaers B: Identification of a gene associated with avian migratory behaviour. Proc R Soc Lond Ser B 2011, 278:2848-2856.

92. Pulido F, Berthold $P$, Mohr G, Querner U: Heritability of the timing of autumn migration in a natural bird population. Proc $R$ Soc Lond Ser $B$ 2001, 268:953-959.

93. Jablonka E, Lamb MJ: Evolution in Four Dimensions: Genetic, Epigenetic, Behavioral and Symbolic Variation in the History of Life. Cambridge: MIT Press; 2005.

94. Emlen ST: Celestial rotation: its importance in the development of migratory orientation. Science 1970, 170:1198-1201.

95. Conklin JR, Battley PF: Impact of winds on individual migration schedules of New Zealand bar-tailed godwits. Behav Ecol 2011, 22:854-861.

96. Gill RE Jr, Douglas DC, Handel CM, Tibbits TL, Hufford GL, Piersma T: Hemispheric-scale wind selection facilitates Bar-tailed godwit circum-migration of the pacific. Anim Behav 2014, 90:117-130.

97. Gill RE Jr, Tibbitt TL, Douglas DC, Handel CM, Mulcahy DM, Gottschalck JC, Warnock N, McCaffery BJ, Battley PF, Piersma T: Extreme endurance flights by landbirds crossing the Pacific Ocean: ecological corridor rather than barrier? Proc R Soc Lond Ser B 2009, 276:447-457.

98. Battley PF, Warnock N, Tibbitts TL, Gill RE Jr, Piersma T, Hassell CJ, Douglas DC, Mulcahy DM, Gartrell BD, Schuckard R, Melville DS, Riegen AC: Contrasting extreme long-distance migration patterns in bar-tailed godwits Limosa lapponica. J Avian Biol 2012, 43:21-32.

99. Piersma T, Klaassen M, Bruggemann JH, Blomert AM, Gueye A, Ntiamoa BY, van Brederode NE: Seasonal timing of the spring departure of waders from the Banc d'Arguin, Mauritania. Ardea 1990, 78:123-134.

100. Shamoun-Baranes J, Leyrer J, van Loon E, Bocher P, Robin F, Meunier F, Piersma T: Stochastic atmospheric assistance and the use of emergency staging sites by migrants. Proc $R$ Soc Lond B 2010, 277:1505-1511.

101. Piersma T, van Aelst R, Kurk K, Berkhoudt H, Maas LRM: A new pressure sensory mechanism for prey detection in birds: the use of principles of seabed dynamics? Proc R Soc Lond B 1998, 265:1377-1383.

102. van Gils JA, Piersma T, Dekinga A, Battley PF: Modelling phenotypic flexibility: an optimality analysis of gizzard size in Red Knots (Calidris canutus). Ardea 2006, 94:409-420.

103. Piersma T, Gudmundsson GA, Lilliendahl K: Rapid changes in the size of different functional organ and muscle groups during refueling in a long-distance migrating shorebird. Physiol Biochem Zool 1999, 72:405-415.

doi:10.1186/2051-3933-2-10

Cite this article as: Winkler et al: Cues, strategies, and outcomes: how migrating vertebrates track environmental change. Movement Ecology 2014 2:10.

\section{Submit your next manuscript to BioMed Central and take full advantage of:}

- Convenient online submission

- Thorough peer review

- No space constraints or color figure charges

- Immediate publication on acceptance

- Inclusion in PubMed, CAS, Scopus and Google Scholar

- Research which is freely available for redistribution 